\title{
Persuasion through artifacts- Sociological and psychological dimensions
}

\author{
Stroe Mihaela 17
}

\section{Abstract}

Research suggests that applicants use various impression management tactics during employment interviews to influence interviewers' evalutions of their performance. Yet, little research has examined inteviewers/ perceptions of applicant's impression management and their degree of nonverbal influence.

This PhD study examines these questions, using both quantitative and qualitative data: Do interviewers accurately perceive applicant's impression management tactics? How are these perceptions integrated into their evaluations of applicant's nonverbal behaviour? Is perception accuracy influenced by artifacts (professional clothing) that interviewees wear?

It has cross-cultural design, because describes the differences in European Commission interviewers' social perceptions and Romanian human resources managers on one hand, and between social perceptions of European Commission public servants and Romanian employees on the other hand, concerning 12 key concepts: persuasion, first impressions, professional image, credibility, authenticity, competence, self- confidence, self-management, self-presentation, self-promotion, impression management tactics, professional appearance

KEY WORDS: job interview, professional clothing, professional appearance, impression management tactics, nonverbal influence

JEL: J64

UDC: 005.953.2:316.472.42

159.925

COBISS.SR-ID 219518988

\footnotetext{
${ }^{17}$ Corresponding author, University of Bucharest,Rumunia,e-mail: contact@mihaelastroe.com
} 


\section{Introduction}

Regardless the fields you are working right now (for example human resources, sales, customer care, tourism, administration, politics, etc.), nonverbal communication is everywhere around us.

Knowing the significance of the artifacts in various contexts, can be considered an essential element of human interaction, and many times it's represented like a subtle barometer of our ability of persuasion and nonverbal influence.

Artifacts (items of clothing, accessories, makeup, tattoos, etc.) are part of nonverbal communication domain, and the study of artifacts is a focus for more scientific communities in areas such as sociology, psychology, anthropology, neuroscience, ethology and of course, communication.

From this perspective, my research's goal is to highlight the existence of a actual interest in understanding of artifacts and their significance in the organizational context and also, to clarify several directions that need to be considered when we talk about staff selection procedures (especially for middle and top management positions).

Despite the increasing importance of new technologies, the selection interview procedures continue to be the key for gathering relevant information about applicants for employment decisions and personnel in organizations (public and private sectors).

While for recruitment procedures were given considerable attention in the last fifty years, I really believe that, we need studies that show us how the human resources decisions are taken during the selection interview, especially about assessing first impressions and how candidates are dressed.

Among the ten channels of nonverbal communication (kinesis, proxemics, territory and personal space, facial expressions, eye movements, haptics, cronemica, olfactory, vocal), I have analyzed in depth the impact of artifacts on judgments made by the human resources practitioners in the context of the selection interview. Why the topic of artefacts in the situation of job interview deserve to be mention in this academic journal?

Because they have an important role in the expression of our status, power and dominance in persuasion and manipulation, lie and impression management. In my $\mathrm{PhD}$ scientific study published in 2012 in Romania, I have presented extensively the social psychology research that discuss that candidates who want a job show a particular tendency to build and apply constant (sometimes even unconscious) strategies to create a positive image about themselves while they interact face to face with those who interview them.

Clothes have an important role at the selection interview, because they can be signs of social status and social symbols of power. They affect self-esteem of those who wear them and the way others behave towards us. The way a person wear her/his clothes contribute to what we call "effect of the first information" (primacy effect). Selection interviews are such a context (or social situation) were the effects of the first information have a big impact on how an employee will be evaluated.

$\mathrm{My} \mathrm{PhD}$ scientific study provides many answers to questions such as:

- How human resources specialists perceive and interpret impression management behaviors of applicants?

- Are their perceptions are correct? 
- What factors affect the accuracy of these perceptions (eg interview typology, clothes, personality of the interviewer)?

— What type of impression management tactics affect the validity job interviews?

- Do candidate's clothing reflects social value?

The following literature review suggests that applicants use various impression management in employment interviews to influence interviewers' evaluation of their performance. Yet, little research has examined interviwers' perceptions of applicant's impression management and their degree of persuasion.

\section{Literature review}

There are several examples in the literature dedicated to impression management that show that applicants influence the opinions of other social actors involved in the recruitment process through verbal and nonverbal during selection interview: C. Fletcher, 1989; R. Gifford and M. Wilkinson, 1985; D.C. Gilmore, C.K. Stevens, G. Harrell-Cook and G.R. Ferris, 1999; C.K. Parsons and R.C. Liden, 1984; R.E. Riggio and B. Throckmorton, 1988).

It is accepted widely that selection interview is an important context for the impression management (Baron, 1989a, 1989b; Fletcher, 1981, 1989, 1990; Giacalone and Rosenfeld, 1989; Gilmare and Ferris, 1989a, 1989b; Ferris and Judge, 1991; Gilmore, Stevens, HarrellCook and Ferris, 1999; Rosenfeld, Giacalone and Riordan, 1995).

Additionally, the applicats tend to influence the employment decision answering at the questions used by human resources specialists and they behave nonverbally in an influential way in order to create a positive first impression (Anderson, Silvester, CunninghamSnell,Haddleton, 1999; Baumeister,Tice, 1986; Leary,Kowalski, 1990; Schlenker, 1980; Stevens,Kristof, 1995).

\section{Methodology}

The attire has become an important aspect in assessing the professional competence of persons looking for a job, as Special Eurobarometer shows in 2009. This sociological research had two components: one quantitative (applying online questionnaires) and one qualitative (semi-structured interview face to face). These findings help human resources practitioner better detect such impression management behaviours and better conduct employment interviews.

In the first part of my research I used as method for data collection on-line self completion questionnaires (random sample). Firstly, I have applied online questionnaires that targeted permanent public servants (having Administrator's roles) from various directorates and units of the European Commission.

From the total of 60 European Commission public servants (30 Romanians and 37 other nationalities) I have investigated the social perceptions that they have regarding the key concepts of research as following: persuasion, first impressions, professional image, credibility, authenticity, competence, self-confidence, self-management, self-presentation, self-promotion, impression management tactics, professional attire. 
Secondly, the sample group was formed by Romanian employees working in national and multinational companies and I also record their social perceptions on key concepts of the research, mentioned above.

In the first part of my research, I used as method for data collection qualitative research, using semi-structured interviews with two distinct groups. One group was formed by heads of departments (head of units and directors) from various European Commission departments who are directly involved in the selection of civil servants for permanent positions in middle and top management. Second group was formed by human resource managers from national and multinational companies who are involved in recruiting Romanian people for middle and top management positions.

\section{Empirical findings}

The first scientific question explored was to see whether the HR refers to artifacts as persuasive factors during the selection interview is supported by data from the study undertaken. From the $50 \mathrm{semi}$-structured interviews conducted with European heads of departments from the European Commission and the Romanian HR managers, I draw the conclusion that professional appearance is an important element on which they base their first impression in the context of recruitment for middle and top management positions.

This statement is in line with the importance that is given to the professional image when human resources specialists have to choose between a candidate who presents with an appropriate professional appearance and one that does not have one according to the standards.

Therefore, according to the results, professional appearance counts depending on the position and the department where candidates apply, fact that is sustained by respondents who claim a rather large attention given its candidate assessment. This percentage varies between $40-60 \%$ of the responses to the question "Does professional image attract your attention as recruiter?"

A possible explanation for these results could be attributed to the important social role of middle and top management positions that claim a professional appearance that has an important role in the successful exercise of their duties.

The second scientific question was to investigate if the human resources specialists correlate in their evaluation of artifacts as concepts like authenticity, trust, competence and credibility. Research results show that respondents (both European and Romanian), correlate professional image with authenticity, confidence and competence. An explanation for this may be, that any interpersonal relationship is based on trust and we communicate through artifacts. From the research, I noticed, that the concern that you appear at the job interview selection with a professional appearance is equivalent to a public declaration that the person is or is not self-confident.

The clothes you choose to wear communicate from the first interaction with the selection panel or human resources specialists, if the person is or is not self-confidence, this being one of the first things that others notice it in 407 seconds from the face to face encounter, fact that is confirmed by the results.

Another result of the research regarding competence attribute to the applicants, both groups of respondents in the semi-structured interviews placed competence, in the top of 
elements that show if the candidate is suitable for the job position that he applied. And research results clearly show that the clothing you wear and the image professional show if you are or you are not a competent person.

However, I believe that the credibility is like the foundation of trust. You are more credible as you have a greater ability to stimulate the perception of those around you. This ability is called "ability to influence". I noticed that the Romanian respondents included influencing skills among the elements that a person must have to be considered suitable for middle and top management position. In the case of respondents from the European Commission we have not made any remarks about "influencing skills", although among the criteria for assessing the performance of candidates, this characteristic is highly appreciated.

Third research question searched to see if human resources specialists perceive impression management strategies used by applicants to impress. Both the Romanian and European respondents noted ways that candidates use as impression management tactics, both verbal and nonverbal. It should be noted that the Romanian respondents indicated more nonverbal ways of impression management tactics such as gesticulation, voice inflections, head up, mirroring behaviours.

Persuading others is just one component of the equation of communication, but in the selection of personnel for positions of middle and top management is essential to perceive correctly if the nonverbal behavior of candidates is authentic or not. I believe that further development of nonverbal intelligence (self-training on better decoding nonverbal signals and emotions) are an essential component for human resources specialists who are involved in recruitment, especially for middle and top management positions.

For the first time in Romania is presented a comparative research between social perceptions of European Commission officials (various nationalities, including Romanian) and Romanians from national and multinational companies, on the 12 key concepts of the study (persuasion, first impressions, professional image, credibility, authenticity, competence, self-confidence, self-management, self-presentation, self-promotion, impression management tactics, professional appearance). The concepts were chosen on research based on the studies conducted by other researchers before and based on my own experience as a result of direct involvement in the recruiting process.

My goal with the first part of the research was to present the social perceptions of the interviewees about these 12 key concepts, focusing on cultural differences. It seems that both officials of the European Commission and the Romanian employees of national and multinational companies use these concepts daily and they are focused to project them at work,

Another novelty for the European Commission is interviewing 25 heads of departments who are responsible for the selection of personnel for middle and top management positions to find the concrete mechanisms they use in this activity based on their first impressions. Also, I wanted to investigate what significance they offer to professional image, what means professional image to them, how they can overcome subjectivity and what impression management strategies they have noticed that candidates used during job interviews.

Because in the recent years the organizational culture of the European Commission registered a deep transformation and it's direction is moving towards an entrepreneurial culture, I have considered necessary a comparative study with human resources managers from Romania, who work in national and multinational companies that are based on such 
organizational culture. They perform selection of staff too, so the candidates they search through selection personnel procedures must match their entrepreneurial culture and also to have personal values aligned with organizational ones.

Maybe you are curious to find out which is the ideal candidate that European Commission is looking for a middle and top management positions versus an ideal candidate for Romanian national and multinational companies. European Commission wants a candidate who has expertise (16 answers), is competent (14 answers), has managerial skills (13 answers), has vision on long term and charisma (11 answers), has strategic thinking (10 answers), is highly motivated (9 answers), is authentic ( 8 answers), you can trust him/her ( 7 answers), is resilient (6 answers), and is responsible (6 answers).

Romanian companies want a candidate who has expertise (17 answers), is competent (16 answers), has influencing skills (14 answers), has a proactive attitude (14 answers), has vision on long term and charisma (14 answers), has leadership skills (10 answers), is highly motivated ( 9 answers), is authentic ( 9 answers), you can trust him/her ( 8 answers) and is responsible (6 answers).

There are numerous similarities between those two profiles of middle and top managers (experience, competence, motivation, charisma/vision, authenticity, accountability, responsibility), but also some differences: whether the European Commission is looking for people with managerial skills, to think strategically and be resistant to stress, in the business environment of Romania are highly appreciated people with influencing skills, with leadership skills, with proactive and innovative attitude.

I found that candidates tend to present an image different from the real one and I believe is substantially too little explored both in Romania, Europe and worldwide. I think the position you are applying (as manager) must not lead to behavioral changes, deviations from your real personality. People would not have to wish for positions that they are not fit or competent, or contrary to their beliefs and inner truth. The artifacts were designed to highlight the uniqueness and particularities of people applying for positions manager, not to transform them in "perfect" people.

\section{Conclusion}

Results from research conducted and presented in this $\mathrm{PhD}$ study help practitioners in human resources field to detect more effective various impression management tactics used by candidates (verbal and nonverbal) and to conduct more efficient job interviews, detecting easier people who are trying to lie and to manipulate their perceptions.

After this research I draw the following conclusions:

1) Nonverbal influence through artifacts depends on the position and the profile you are looking for;

2) Candidates receive a higher credit during the selection interview if they know how to choose appropriate professional clothes/attire for that job context;

3) The image or appearance is a true professional asset if is supported by proactive attitude and competence;

4) People who make the difference are those who presents, in a authentic way, the truth about themselves (their true self revealed and assumed). 
Other studies may be performed to identify which type of interview can allow disclosure of impression management strategies that candidates apply (for example, using structured interview), especially when they want to work in a multicultural environment.

It is necessary to study further how cultural differences affect impression management strategies and which are the nonverbal tactics used to influence recruiters' perceptions during job interview.

Potential training interventions can be developed to help recruiters to improve their ability to detect impression management tactics, especially deceiving behaviours, by simply increasing their nonverbal intelligence.

\section{References}

[1] Anderson, N. R., Silvester, J., Cunningham-Snell, N. and Haddleton, E. (1999). Relationships between candidate self-monitoring, perceived personality and selection interview outcomes. Human Relations, 52, 1115- 1131.

[2] Baron, R. A. (1989a). Personality and organizational conflict: effects of type A behavior pattern and self- monitoring. Organizational Behavior and Human Decision Process, 44, 281-297.

[3] Baron, R. A. (1989b). Impression management by applicants during employment interviews: the "too much of a good thing" effect. In R. W. Elder and G. R. Ferris (eds.). The employment interview: Theory, research and practice (pp. 204-215). Newbury Park, CA: Sage.

[4] Baumeister, R. F.,Tice, D. M. (1986). Four selves, two motives, and a substitute process self-regulation model. In R. F. Baumeister (ed.). Public image and private self (pp. 63-74). New York: Springer-Verlag.

[5] Ferris, G.R.,Judge, T. (1991). Personnel/Human Resources Management: a political influence perspective. Journal of Management, 17, 2, 447- 488.

[6] Fletcher, C. (1981). Candidates' beliefs and self-presentation strategies in selection interviews. Personnel Review, 10, 14-17.

[7] Fletcher, Clive. (1989). Impression management in the selection interview. In Robert A. Giacalone and Paul Rosenfeld (eds.). Impression Management in Organizations (pp. 269-281). Hillsdale: Erlbaum.

[8] Fletcher, C. (1990). The relationships between candidate personality, self-presentation strategies and interviewer assessments in selection interviews: An empirical study. Human Relations, 43, 739-749.

[9] Giacalone, R. A.,Rosenfeld, P. (1989). Impression management in the organization. Hillsdale, NJ: Lawrence Erlbaum Associates.

[10] Gifford, R., Fan Ng, C. ,Wilkinson, M. (1985). Nonverbal cues in the employment interview: links between applicant qualities and interviewer judgments. Journal of Applied Social Psychology, 70, 729-736. 
[11] Gilmore, D. C., Stevens, C. K, Harell-Look, G.,Ferris, G. R. (1999). Impression management tactics. In Robert W. Eder and Michael M. Harris (eds.). The Employment Interview Handbook (pp. 321-336). Thousand Oaks: Sage Publications.

[12] Gilmore, D. C..Ferris, G. R. (1989a). The politics of the employment interview. In R. W. Eder şi G. R. Ferris (eds.). The employment interview: Theory, research and practice (pp. 195-203). Newbury Park, CA: Sage.

[13] Gilmore, D. C.,Ferris, G. R. (1989b). The effects of applicant impression management tactics on interviewer judgements. Journal of Management, 15, 557-564.

[14] Gilmore, D. C., Stevens, C. K, Harell-Look, G.,Ferris, G. R. (1999). Impression management tactics. In Robert W. Eder şi Michael M. Harris (eds.). The Employment Interview Handbook (pp. 321-336). Thousand Oaks: Sage Publications.

[15] Leary, M. R.,Kowalski, R. M. (1990). Impression management: A literature review and two-component model. Psychological Bulletin, 107, 34-47.

[16] Parsons, C.K.,Liden, R. C. (1984). Interviewer perceptions of appliquant qualifications: a multivariate field study of demographic characteristics and nonverbal cues. Journal of Applied Psychology, 69 (4), 557- 568.

[17] Riggio, R. E.,Throckmorton, B. (1988). The relative effects of verbal and nonverbal behavior, appearance and social skills on evaluations made in hiring interviews. Journal of Applied Social Psychology, 18, 331-348.

[18] Rosenfeld, P., Giacalone, R. A.,Riordan, C. A. (1995). Impression management in organizations: Theory, measurement and practice. London: Routledge.

[19] Schlenker, B. R. (1980). Impression management: The self-concept, social identity and interpersonal relations. Monterey, CA: Brooks/Cole.

[20] Stevens, C. K.,Kristof, A. L. (1995). Making the right impression: A field study of applicant impression management during job interviews. Journal of Applied Psychology, 80, 587-606.

\section{Article history:}

- $\quad$ Received 8 September 2015

- $\quad$ Accepted 21 October 2015 